\title{
LEFT INTERNAL CAROTID ARTERY AGENESIS IN A CHILD
}

\section{Umair Mohiuddin ${ }^{1}$, Udayakumar Seetharamarao², Pushpalatha Kariyappa ${ }^{3}$}

\section{HOW TO CITE THIS ARTICLE:}

Umair Mohiuddin, Udayakumar Seetharamarao, Pushpalatha Kariyappa. "Left Internal Carotid Artery Agenesis in a Child". Journal of Evolution of Medical and Dental Sciences 2015; Vol. 4, Issue 02, January 05;

Page: 308-311, DOI: $10.14260 /$ jemds/2015/48

ABSTRACT: Internal carotid artery (ICA) agenesis is a rare congenital anomaly. Most of the patients remain asymptomatic due to collateral blood flow and are discovered incidentally. Increased incidence of intracranial vascular anomalies are associated with ICA agenesis. We report a symptomatic case of ICA agenesis in a child with collateral supply from basilar artery.

KEYWORDS: agenesis, internal carotid artery.

INTRODUCTION: ICA agenesis is a rare congenital anomaly with an incidence of $0.01 \% .{ }^{1}$ Tode is credited with the first documented case of carotid agenesis discovered on postmortem examination in $1787 . .^{2}$ In 1954, the first case of ICA agenesis at cerebral angiography was reported by Verbiest. Slightly more than 100 cases of congenital absence of the ICA have been reported in literature. ${ }^{3}$ Only few symptomatic cases of ICA agenesis have been reported in children, because of the collateral pathways which maintain the cerebral perfusion. ${ }^{4}$ Collateral supply is more commonly supplied by circle of Willis, but may also be provided by embryonic vessels or the external carotid artery. ${ }^{5} \mathrm{We}$ report a symptomatic case of left ICA agenesis with collateral supply from basilar artery.

CASE REPORT: A 14 year old child presented with history of recurrent syncopal attacks, headache and left sided chest pain since past 3 years. On detailed clinical examination had absent common carotid artery (CCA) pulsations on left side, pulsations of right CCA and other peripheral pulsations were well felt. Child was evaluated for carotid artery anomalies, CT angiography done showed hypoplastic left common carotid artery, absence of left internal carotid artery, and the basilar artery continuing as left middle cerebral artery.

DISCUSSION: ICA agenesis is a very rare congenital anomaly with an incidence of $0.01 \% .^{1}$ An exact cause of these developmental anomalies is not known, these are thought to represent the sequelae from an insult to the developing embryo. Some mechanical and hemodynamic stresses placed on the embryo, including the effects related to the exaggerated folding of the embryo towards one side and constriction by amniotic bands have been postulated as the cause for unilateral agenesis, cause for bilateral agenesis is not known. 6

ICA agenesis can be unilateral or bilateral, but unilateral variety is more common.7 ${ }^{7 C A}$ agenesis is known to occur more frequently on the left side. The ratio between right and left ICA agenesis is 1:3.8 Very few cases of ICA agenesis have been reported in children, because of the collateral supply, which is sufficient to maintain cerebral perfusion. ${ }^{4}$ ICA agenesis was discovered in our patient during evaluation for syncope.

Six pathways of collateral circulation in association with absence of the ICA has been described by Lie. ${ }^{4}$ In type A, unilateral absence of the ICA is associated with collateral circulation to the ipsilateral Anterior cerebral artery (ACA) through a patent Anterior communicating artery 


\section{CASE REPORT}

(ACOM) and to the ipsilateral Middle cerebral artery (MCA) from the posterior circulation through a hypertrophied Posterior communicating artery (PCOM). In type B, pattern of collateral flow is that the ipsilateral ACA and MCA are supplied across a patent ACOM. Type C represents bilateral agenesis of the ICA with supply to the anterior circulation via carotid-vertebrobasilar anastomoses. Type D represents unilateral agenesis of the cervical portions of the ICA with an inter cavernous communication to the ipsilateral carotid siphon from the contralateral cavernous ICA. In type E, diminutive ACA's are supplied by bilateral hypoplastic ICA's, and the MCA's are supplied by enlarged PCOMs. The type F pattern provides collateral flow to the distal ICA via transcranial anastomoses from the internal maxillary branches of the External carotid artery (ECA) system, the so-called 'rete mirabele'. Lie's original six collateral pathways have been simplified into three main types, collateral supply through the circle of Willis, through persistent fetal circulation and through reconstitution of the ICA through skull base collaterals from the ECA. ${ }^{9}$

Increased incidence of intracranial aneurysms is seen in association with ICA agenesis. It has been reported in $25-43 \%$ of the patients, which is much higher than that found in general population, 2-4\%. ${ }^{10,11}$ Diagnosis of ICA agenesis requires documenting the absence of the ICA by angiography, Magnetic resonance angiography (MRA) or Multi slice computed tomography (MSCT) angiography.

CONCLUSION: ICA agenesis is a rare vascular anomaly. Patients often remain asymptomatic due to collateral supply. ICA agenesis is associated with higher incidence of aneurysm formation therefore patients with ICA agenesis should undergo evaluation for the presence of intracranial aneurysms. Patients may present with cranial nerve deficits, cerebral ischemia, or subarachnoid hemorrhage secondary to complications of associated aneurysm formation. In addition to associated cerebral aneurysms, these anomalies have important implications during carotid endarterectomy and transsphenoidal hypophyseal surgery, and in the setting of thromboembolic disease.

\section{REFERENCES:}

1. Smith KR, Nelson JS, Dooley JM. Bilateral 'hypoplasia' of the internal carotid arteries. Neurology 1968; 18: 1149-56.

2. Midkiffotid RB, Boykin MW, Mc Farl and DR, Bauman JA. Agenesis of the internal carotid artery with intercavernous anastomosis. AJNR Am J Neuroradiol 1995; 16: 1356-1359.

3. Claros P, Bandos R, Gilea I, et al. Case report: major congenital anamolies of the internal carotid artery - agenesis, aplasia and hypoplasia. Int J Pediatr Otorhinolaryngol 1999; 49: 69-76.

4. Lie TA. Congenital anamolies of the carotid arterys. Amsterdam: Excerpta Medica; 1968.p. 4449.

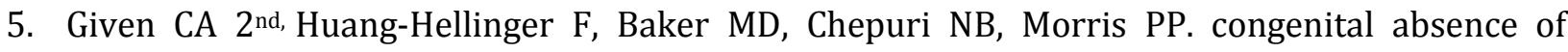
internal carotid artery: case reports and review of collateral circulation. AJNR Am J Neuroradiol 2001; 22: 1953-1959.

6. Teal JS, Naheedy MH, Hasso AN. Total agenesis of the internal carotid artery. AJNR Am J Neuroradiol 1980; 1: 435-442.

7. Cali RL, Berg R, Rama K, et al. Bilateral internal carotid artery agenesis: a case study and review of the literature. Surgery 1993; 113: 227-233.

8. Florio F, Balzano S, Nardella M, Strizzi V, Cammisa M, Bozzini V, et al. Congenital absence of the internal carotid artery. Cardiovasc Intervent Radiol. 1999; 22: 74-78. 


\section{CASE REPORT}

9. Chen CJ, Chen ST, Hsieh FY, Wang LJ, Wong YC. Hypoplasia of the internal carotid artery with intercavernous anastomosis. Neuroradiology 1998; 40: 252-254.

10. Kunishio K, Yamamato Y, Susami N, Asari S. Agenesis of the left internal carotid artery, common carotid artery, and main trunk of external carotid artery associated with multiple cerebral aneurysms. SurgNeurl 1987; 27: 177-81.

11. Lee JH, Oh CW, Han DH. Aplasia of the internal carotid artery. ActaNeurochir 2003; 145: 117-25.

12. Quint DJ, Boulos RS, Spera TD. Congenital absence of the cervical and petrous internal carotid artery with intercavernous anastomosis. AJNR Am J Neuroradiol 1989; 10: 435-439.

FIGURE 1: CT angiography shows hypoplastic left CCA (arrow), left ECA (arrow head), absence of entire ICA on left side and basilar artery continuing as left middle cerebral artery (bent-up arrow).

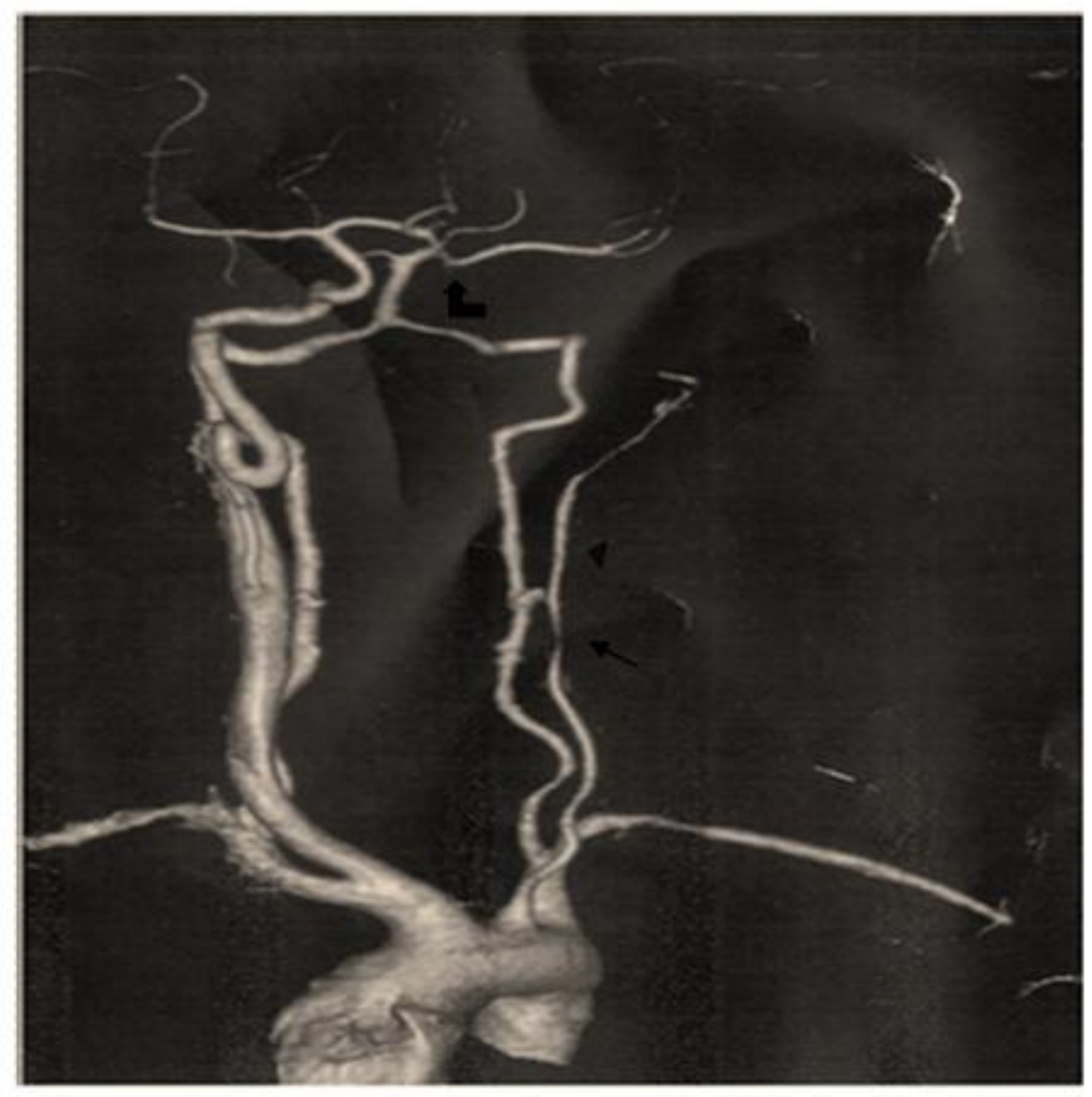

FIGURE 1 
Figure 2: ICA agenesis: pathways of collateral blood flow. After Lie (5) and Quint et al (12); see text.

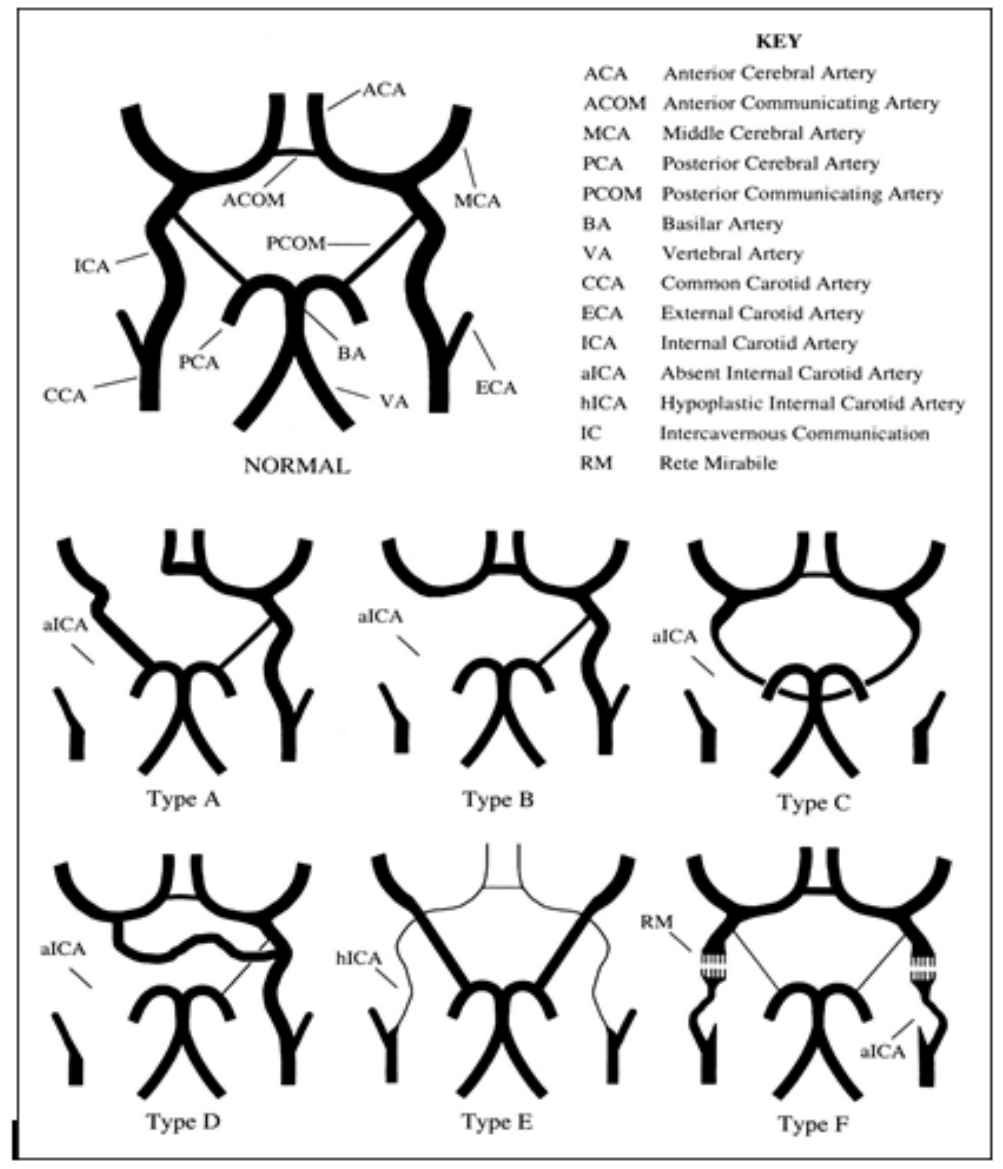

\section{FIGURE 2}

\section{AUTHORS:}

1. Umair Mohiuddin

2. Udayakumar Seetharamarao

3. Pushpalatha Kariyappa

\section{PARTICULARS OF CONTRIBUTORS:}

1. Post Graduate, Department of Paediatrics, ESIC MC \& PGIMSR, Rajajinagar, Bangalore.

2. Associate Professor, Department of Paediatrics, ESIC MC \& PGIMSR, Rajajinagar, Bangalore.

3. Professor and HOD, Department of Paediatrics, ESIC MC \& PGIMSR, Rajajinagar, Bangalore.

\section{NAME ADDRESS EMAIL ID OF THE} CORRESPONDING AUTHOR:

Dr. Umair Mohiuddin, Room No. 319, ESIC Boys Hostel, Rajajinagar $1^{\text {st }}$ Block, Bangalore - 560010 .

E-mail: drumairm@gmail.com

Date of Submission: $15 / 12 / 2014$. Date of Peer Review: 16/12/2014. Date of Acceptance: 23/12/2014. Date of Publishing: 05/01/2015. 